\title{
Risk. Dealing with Uncertainty in Modern Times
}

\author{
Wolfgang Bonß $\Re^{*}$ \\ 1 Universität der Bundeswehr München, Fakultät für Staats- und Sozialwissenschaften, Werner-Heisenberg-Weg 39, 85577 \\ Neubiberg, Germany
}

KEYWORDS

Risk

Uncertainty

Safety

Security

Risk society

Risk culture

\begin{abstract}
People have always lived under conditions of uncertainty. But how to deal with uncertainty and how security is produced varies depending on the social formation. This paper deals with the handling of uncertainty in modern societies. Modern societies always try to conceptualize uncertainties as action-related, responsible and calculable/predictable 'risks'. This was a quite successful approach for a long time. However, under the conditions of 'risk society', this approach is increasingly difficult to work. Especially in the case of 'new risks', the attempt to conceptualize any uncertainty as a predictable and cumulatively controllable risk, can hardly be realized. That's why modern societies must ask for and reflect on a 'new culture of uncertainty'.
\end{abstract}

\section{The multiplication of discourses on security}

If one enters the keyword security/safety in Google, 3.41 billion results are delivered. The keyword risk occurs 838 million times, while there are 'only' 356 millions matches for democracy'. Even though the significance of this observation might be challenged by the argument of having countless duplicates of results, these numbers are nevertheless an indicator of the relevance of these issues, not only on the Internet but also in the public

\footnotetext{
* Contact address: Wolfgang.Bonss@unibw.de (W. Bonß)

1 Version April 30, 2013 - Indications already rounded up at Google. If you limit the search to the German key words, a slightly different result is delivered, but which is similar with regard to the uneven distribution: 191.000 .000 for Sicherheit, 66.700 .000 for Risiko and 17.000.000 for Demokratie.
} 
discourse. This result is as remarkable as the fact that security/safety is debated four times more often than risks. A keyword like democracy is less popular - in the German speaking circles, the number of articles represents only $1 / 9$ and in the German and English speaking circles it represents only $1 / 10$.

However there are no early comparison data in this sense, which is not surprising considering the history of the internet. But there are a lot of arguments that sustain the idea that the security issue has become more and more relevant in the last 50 years. This can be studied for example with the development of the automobile safety. Even though invented in 1903, the safety belt was unknown for nearly 60 years; however, today, a car without ABS, ESP and (at least) four airbags is considered 'unsafe'. Another example is the change of the biological researches, which for the differentiation between L1, L2 and L3 labs has lead to completely new security standards. Not quite so far developed is the matter 'Information Security', which until recently hardly played a role, but now it is hotly debated and is regulated by its own ISO standards (ISO 2700x, ISO / EIC 15408). And finally the security requirements and expectations rise in social life as well. This applies not only to the external, but also to the internal security, and here again the demands grow with the social and individual security in a form, that some already talk about a precarious trend towards a 'fully comprehensive' mentality or of 'un-courage to care (Karstadt Quelle 2008).

It is debatable whether this criticism is justified, especially since the growing security requirements cannot be equated with growing certainties. This is emphasized also by Wolfgang Sofsky in his treatise on 'the principle of security' when he writes:

'People have always lived in a dangerous world. But only since they have topped the masters of this world, they must be attributed all misfortune.' (Sofsky 2005: 29).

So security becomes a dominant theme only starting with a certain moment of the social development. This requires a change in attitude to the world that is not understood anymore as a predetermined cosmological context 
that you have to adapt to, but rather a designable and variable context, which is attributed to the actor himself. That is why security means more than 'absence of threat' (Brockhaus 2002) and a state of not being threatened. As Franz-Xaver Kaufmann noted in 1973, it is rather a matter of a value idea that is differenced in various dimensions, which becomes an explicit social project together once the modern societies occur (see Kaufmann 2003: 10). This aims to make uncertainties manageable and completely eliminate them, if possible - a claim which, however, that has changed historically and has just been qualified by its increased persecution.

Figure 1: Conceptions of certainty

\begin{tabular}{|c|c|c|c|}
\hline $\begin{array}{l}\text { Category / } \\
\text { Term }\end{array}$ & SAFETY & SECURITY & CERTAINTY \\
\hline Meaning & $\begin{array}{l}\text { 'technical' safety in the } \\
\text { sense of the reliability of } \\
\text { technical systems }\end{array}$ & $\begin{array}{l}\text { 'public' security in the } \\
\text { sense of political/social } \\
\text { security }\end{array}$ & $\begin{array}{l}\text { cognitive certainty and its } \\
\text { limits }\end{array}$ \\
\hline Examples & $\begin{array}{l}\text { Safety belt, ABS, ESP; } \\
\text { general: the technical } \\
\text { reliability of components, } \\
\text { units, subsystems and } \\
\text { whole systems (without } \\
\text { social influences) }\end{array}$ & $\begin{array}{l}\text { a) the social embedding/ } \\
\text { contextualization of } \\
\text { technical risks } \\
\text { b) Political security: } \\
\text { internal and external } \\
\text { security } \\
\text { c) Social security: social } \\
\text { security, health security } \\
\text { d) Biographical security: } \\
\text { expectability and } \\
\text { comprehensibility of one's } \\
\text { own life course }\end{array}$ & $\begin{array}{l}\text { The (un-)certainty, in } \\
\text { particular of scientific } \\
\text { knowledge } \\
\text { The systematic doubt as } \\
\text { critique of the certainty }\end{array}$ \\
\hline
\end{tabular}

How wide the security program of modernity is, is shown far more clearly in the English language than in the German language. While Germans have only one word ('Sicherheit'), in English there are at least two to three options (Figure 1). The largest field is occupied (not necessarily content related, but rather from quantitative point of views) by the technical (un)certainties, as they become the theme under the keyword safety or unsafety; here it is about the reliability of components, units, subsystems and 
whole systems, which are 'asocial', meaning they are considered and analyzed independently from the human influences. However, if human influence factors occur, as it is the case for many social-technical systems and for political-social uncertainties, then in the English language the label security respectively insecurity is needed. This is itself a very broad field that should be differentiated in detail. Because the social embedding of technical risks falling well here under as the question of political and social certainties, and with the growing complexity of individual life courses, the 'biographical security' has finally become a new more and more important research field (see Bonß et al. 2004).

(Un-)certainties should be considered as a third dimension. Uncertainties define the cognitive side of the problem. The statement of being certain in case of uncertainties is a contradiction. Because the uncertainties are characterized by the fact that they cannot be clarified definitely with regard to cognitive aspects, but they can be estimated through probabilities. Seen from this angle, the insecurity permanently supposes uncertainty. Because if there was a definitive clarification beyond probabilities, then uncertainties would turn into certainties, which do not exist in this form in the present societies.

The multiplication of the (un-)certainty discourses, as it can be observed, especially since the 50s of the last century, is also remarkable because it also goes hand in hand with a shift in emphasis. Today security becomes a permanent question, because there is no endless security, but only for a time. In other words: security is experienced less and less as an order problem, but more and more as a risk problem. Order problems are characterized by the fact that there is a unique optimal solution for them; once this 'order solution' has been found, it can be assumed that a permanent security is achieved. In high-risk problems, however, there is no clear final solution; rather they are characterized by the fact that the envisaged solutions are always far less than optimal, as they move on to new uncertainties that are either created or only just visible. An example in this sense if the introduction of antilock braking system (ABS) which was 
considered as an absolute safety mean and which was rewarded also by insurance companies, which bonused cars with ABS in the beginning. However the insurances fell, since it had been discovered that the accident probability of ABS equipped cars was not lower, but higher. This had to do with the fact that the better breaking systems led to more pileups with vehicles that were not equipped with ABS. On the other side, the ABS protected risky drivers, which often over-compensated the safety increase.

These examples make it clear that safety improvements do not always lead to more security. They can cause much more adverse effects, which generate new uncertainties. This is very often the case and makes it more obvious that security is not perceived as an order problem anymore, but rather as a risk problem. In front of this background the value idea of security seems to have been realized in a rather ambivalent form. This one we cannot assume under any circumstances a linearly increasing security growth. However one can hardly deny the increase of the security level. But because of the disappearing of old uncertainties, new ones occur and the sensitivity towards uncertainty increases as well. Today much more safety/security problems are acknowledged and a form of certainty/uncertainty spiral seems to build up: the higher the safety/security level and the safety/security requirements, the more uncertainties and the more 'new' uncertainties are discovered, which require more efforts during the production of safety, security and certainty. However, it remains open whether this certainty/uncertainty spiral can be driven further and further. This is exactly the subject this contribution approached and it focuses on the social construction of certainty and uncertainty.

Uncertainty, risk, danger. Or: How are we different from the Lele in Africa?

If one deals with security and uncertainty, the question about the meaning of insecurity and uncertainty appears automatically. Where do insecurities 
occur, what do they refer to and what does uncertainty mean more exactly? Basically, uncertainty doesn't mean knowing the future events, but knowing the possibility of negative future events. The one who feels insecure does not know what the future might bring, but he or she is sure that the future may bring various events. This is a specific human feature, which cannot be applied for animals. Animals are instinctive and don't know uncertainty. They have strong reaction programs that might not always be appropriate, but as a rule, they are clear and reliable. In comparison, the instinct of humans is only available in a low measure. Indeed the human also presents some 'automatics' in his behaviour (Gehlen 1957: 116). But as long as he/she can act one way or another, without knowing the future, the human is 'open for the world' (Gehlen 1940: 227) and therefore he/she has a (ultimately existential) experience with uncertainty. Or as Marx Wartofsky expresses it:

'To take or avoid risk requires more than animal response... risk, as a category, applies only to actions of socially conscious agents, capable of understanding an account of their own actions' (Wartofsky 1986: 130-131).

More interesting than the existential experience with uncertainty is the fact that the handling of uncertainty is different, depending more on the social context and this applies both for what is perceived as uncertainty and for how one responds to insecurity. This problem can be illustrated by the example described by Douglas and Wildavsky (1982: 6ff.) regarding the Lele in the current Republic of Congo. The members of this Central African tribe have a relatively low expectancy of life and they are daily exposed to life threatening dangers, ranging from snake bites up to infections ${ }^{2}$. Whether and under what conditions these threats manifest is uncertain. But this is ultimately less important than the selectivity of perception. Since for the Lele there are three decisive and socially manageable menaces: one would be the possibility to be hit by the lightning, the second is the problem of infertility and the third is the risk of contracting bronchitis. These are exactly the

\footnotetext{
2 Appealing to Western diagnosis procedures, Douglas and Wildavsky (1982: 7) present the following: 'fever, gastroenteritis, tuberculosis, leprosy, ulcers, bareness, and pneumonia'.
} 
insecurities that the Lele have to deal with and for which they take 'security measures'.

If you are interested in why these dangers are decisive from a socialcultural point of view, please read the analysis of Mary Douglas (1963). But at the moment it is more interesting to have a look at the strategies of the Lele, to explain and to tackle the menaces they perceive. Because these strategies hardly correspond to the criteria of members of the Western rationalized cultures. This way, the bronchitis prevention does not consist in preparing yourself otherwise for the environment or changing the environmental conditions. More magical practices are used, like amulets, which must be worn as a precaution. For the members of the Lele tribe, bronchitis and infertility have no 'somatic' causes, but they are explained more as moral failures, which are not directly imputable to the doers. If they are perceived, then they are acknowledged and visible only ex post. The fact that the actors do not know what they could have done wrong does not change the fact that the misconducts of non-healing forces are punished relentlessly. They attract illness, respectively punishments and nobody knows where or why they come and which can be combated with magical practices only.

In the pre-modern Europe there had been similar pattern of dealing with uncertainty. This can be studied both on the large diffusion of superstitious security strategies as well as on the traditional fear of nature, as it had been diffused until the 18th century. As the diffusion of talismans shows, the pre-modern security strategies do not disappear in the modern times either. But at least officially they stand in the background. Because the modern times develop other forms for dealing with uncertainty. As a typically modern form of the concept of risk applies, which is mostly described with reference to danger. Risk and danger are two different forms of the constitution and handling of uncertainty, which coexist only in the modern times. Or, taking the following example: the Lele experience dangers very often, even if they do not perceive them as such, as compared to 
modern societies; but they know no risks, since this type of uncertainty is tightly bound to the modern world and understanding (see Bernstein 1997).

The fact that risks opposed to dangers are part of a rather young approach is shown by the etymology of the term risk. Detected and distinguished from other uncertainty patterns there was a first talk of a 'risk' in the Italian city-states of the 12-13 th century, namely in the context of the long-distance trade, especially sea trade. The long-distance trade was a pricy and insecure matter. It required important preparations which did not necessarily lead to success. Ships could have sunk, transports could have been robbed, goods could have been damaged, roads could have been blocked, etc. Exactly these insecurities were not considered dangers, but rather risks. The tradesman who assumed the risks was somebody who 'risked' something, meaning he 'dared' (Ital. risciare = to dare); he did not submit to the risks but he challenged them and speculated at the same time his luck. However it remained open, whether the calculation was correct and whether the luck was on his side. But in a successful case, he could get rich; however, in case of a failure, he would lose everything, which was accepted as 'normal' both by him and his contemporaries.

Such a calculating attitude towards insecurities could appear only at a certain moment in time, under specific social circumstances. This points to what Max Weber called 'Occidental rationalization' and 'demystification of the world'. For Weber the Occidental rationalization did not mean 'a growing general acknowledgement of the life conditions in which one lives. It means something else: knowing or believing that if one wants to, he can find it out, that, as a principle, there are no invisible, secret forces, that, as a principle, one can control things by calculation' (Weber 1919: 317). However neither the Italian tradesman of the early times, nor his ancestors were able to put a stop to storms or control the forces to prevent attacks. But such insecurities had no longer been considered fate menaces but they were seen and attributable and calculable challenges, meaning problems that could only occur if one did an incorrect calculation or did not take any prevention measures. 
The contradiction of 'fate menace' and 'attributable dare' already reflects a significant change. If someone witnesses, like for Germany of the 16th century, assuming something 'uf unser Rysign' (on my risk), then he/she proves that he/she does not perceive the questioned insecurity/uncertainty as a danger that cannot be influenced, which is caused by the gods or other forces; but he perceives it as a problem caused by himself and therefore a problem for which he/she is to blame. The world is not determined by non-calculable cosmological forces anymore, but the horizon of the own action possibilities is the new limit. This way, new insecure realities can occur, which have other forms - that uncertainty is assumed by the tradesman who is willing to take risks. His insecurities would not exist if he had not wanted to buy or sell goods and they occur only because, being aware of and trusting his own possibilities, he believes he can handle the situation.

In a systematic way this means that as a first and most important feature of the risk concept the action and decision comes before the risks. Insecurities of the type 'danger' exist independently from the doers; insecurities of the type 'risk' exist in the light of the intention of actions and their implementation. Or, in another way: dangers do not depend on subject and situation; risk, on the other hand, supposes a subject-related decision for an uncertainty. This point is highlighted mostly in the modern decision theory, as it has been developed in various variants from the company management decision-making theory to the general game theory, up to the 'rational choice concept'3. From this point of view, risks are mostly defined as 'decisions made in uncertainty', which are evaluated in another manner than the dangers not depending on the decisions made. While dangers are evaluated negatively as menaces that do not depend on the subject, the same does not apply for risks. Just because they depend on the actions, risks appear not only as menaces, but also as chances. Taking risks means testing

\footnotetext{
${ }^{3}$ For the decision theory see Eisenführ \& Weber (2003: esp. 207ff.), for the game theory Dieckmann (2009), for the rational choice approaches see Wiesenthal (1987), Kunz (2004).
} 
the decision, which can go wrong, but which can also bring significant advantages, if successful.

A second feature of the risk concept is tightly linked to the handling and decision, namely their imputability and accountability. Imputability and accountability play a very important role in the daily limitation of risks and dangers. Dangers cannot be accounted for, since they do not depend of the subject and since they are insecurities that cannot be controlled. But everything changes when it comes to risks. If a risky business goes wrong, then a responsible person can (and must) be identified. Because when trying to reach something new, risks are an aware dare and the consequences must be accounted for by the doers, as long as they are identified as decision makers. But this means also: insecurities are perceived as risks only when they can be imputable to a social construction (ideally to an actor). If this imputation is not reasonable, for any other reasons, then the risks appear as dangers or they can turn into dangers.

The last situation is not so rare. Something that is perceived by someone as a voluntary dare, for which that someone is responsible, may be an unwanted menace for someone else. For example, for the early modern tradesman of the seas, his decisions made in uncertainty were risks; for the seamen depending on him, the same insecurities were rather dangers. In other words: one and the same situation can turn into a risk or danger in equal measure. This way, a man driving against the traffic on the motorway is a risk for himself, but becomes a danger to the other traffic participants. The same applies to investment decisions (as to the act of not assuming any investments), which are a risk for the doers and a danger for the jobs. A similar double structure marks also the processes like approving a new medicine, deciding the location of a garbage dump or granting an operation permit for a gene technological production hall; in this case we speak about risk decisions, which do not represent a danger for the concerned people at the moment of the decision; therefore, for these individuals the uncertainty of the type risk can subtly turn into an uncertainty of the type danger. 
A third feature of the risk is the calculability. This feature has already been approached by Max Weber. According to Weber, one can take insecurities of the risk type only if persons have a strong belief in the calculability of the world, which is concretely expressed in the Principle of the rational calculation (see Weber 1980 [1922]: 13). This formulation, which has been quoted so many times, is unclear insofar as pre-modern security conceptions are not 'irrational' by definition. This way Lele's coping with insecurities in their own reference system is highly rational and, as far as they can calculate alternatives in the context of magical spells, their actions present calculating elements as well. But this calculation is no purely intellectual, decontextualized coping with uncertainty situations and is not carried out calculatorily in the literal sense. The Leles do not act on purpose, means and consequences and as long as they do not act in an intellectual purpose in the sense of Weber (1980 [1922]: 12f.), basically they are not able to quantify insecurities.

Even if the example of the Lele should not get too strain, the comparison highlights central features of the rational, namely more exactly: rational and goal-oriented security strategies of the modern time. In the end, these strategies run to a subject and situation dependent handling with uncertainty situations. This handling is subject and situation independent and therefore decontextualized since it supposes a certain calculation, independently from a concrete case. We speak about the probability calculation, which was unknown before the Renaissance, having a rapid growth in the 17/18th century and becoming widespread in the 20th century, when the probability term 'gradually displaced the term of causality' (Reichenbach 1935: V). With the concept of probability emerge completely new contingencies when handling uncertainty, since the lifeworld experienced prior structure and complexity is overridden and set in a specific form. The one who understands the world as a relation of probabilities perceives reality in a reflexive distance and under a different time horizon. The reality is virtualized and it is disintegrated into an abstract 
space of possibilities, which can be combined and calculated and whose realization is slowly materialized 'behind the back' of the doers".

In an important way the concept of the risk calculation was described by Frank H. Knight with his differentiation of 'risks' and 'uncertainties'. For Knight, risks were 'measurable uncertainties' (Knight 1965 [1921]: 197ff.) The measurable uncertainties are uncertainties that can be calculated and handled in a specific manner. Technically speaking, we must understand these uncertainties as situations that can be described as a closed event or sample space, whose possible consequences are not known in particular, but as a whole. The paradigmatic example in this sense is the game of dices. The game of dices is an uncertain matter since nobody can know beforehand how the dices will fall. However, the event space and the totality of results is known. For more than six different results cannot exist; should a dice show even a seven, you can safely assume that it has been labelled incorrectly. And because it is a closed system with clearly defined framework and clear results, a distribution function can be created without any problem, one can calculate the probability of an event that is even uniformly distributed in this case - the chance to roll a certain number of known 1/6.

Far more often than the clear-cut risks, as they exist at the craps, roulette or the lottery are, of course, are those uncertainties that cannot meet the strict requirements of measurability and they were defined by Knight as 'uncertainties'. 'Uncertainties' are characterized by the fact that for them no closed event space is given and/or the relative probability of possible individual results is unknown. Or formulated in analogy to the dice game example: in the case of 'uncertainties' results such as 'seven' or 'four point three' are not excluded because unexpected results, respectively result variants, may arise - this refers to the well-known 'side-effect problem'. At the same time, there is confusion over the responsibility for the possible outcomes of impact factors, which are often only partially known or

\footnotetext{
${ }^{4}$ See Bonß (1982: 87ff). For the development of the probability concepts see Hacking (1975), Porter (1986), as well as Desrosières (2005).
} 
determinable, so that the relative probability of a result can hardly be calculated as required by Knight.

The probabilistic-oriented risk research ${ }^{5}$ targets to transform calculable 'risks' into 'uncertainties'. But this at first glance obvious strategy is limited and not always useful in practice. Thus, the risk models are inevitably under complex systems, especially in open risk and cannot detect and check all possible factors. Moreover the themed observation, which has been consolidated in the last years, appears and sustains that decisions under uncertainty are evidently not made only on the basis of rational calculation. Rather, they are always 'gut decisions' (Gigerenzer 2007), where 'intuition' (Traufetter 2009) is as important as calculation. In addition, the experience gained from the investigation of accidents in high-risk technologies (see Perrow 1987 [1984]), shows that the most critical events must be characterized rather as 'uncertainties' than as 'risks'. Thus, accidents are often triggered by 'unexpected interactions' between elements of the system that could be provided in any risk scenario and therefore not calculated and checked. As such an 'unexpected interaction' also the attack on the World Trade Center in New York could be interpreted. The fact that fully occupied and fully fuelled passenger aircrafts are used to attack skyscrapers was unthinkable before 11.9.2001 and was not taken into account for the construction of houses. However, you can install the relevant uncertainty in these scenarios since then. But the example shows that risk decisions and systems are more open and more than assumed in the probabilistic models. But if all contingencies can never be considered, then this raises the reverse question: which uncertainties are taken into account in practice, how and what consequences arise from this for the security issue?

\footnotetext{
${ }^{5}$ For various perspectives on risk research, see Bechmann (1993), Banse and Bechmann (1998), Metzner (2002: 27ff.), as well as Renn et al. (2007: 20ff.), presenting over 50 concepts and approaches of risk research.
} 


\section{Standard positions and alternatives. Or: about the handling of uncertainty in the modernity}

In the assessment of uncertainty and unpredictability for the human action very different positions can be identified. Prevalent (and fundamental to the conventional risk research) is what might be called the 'default position' of modernity. The following statement of Talcott Parsons illustrates it:

'Exposure to uncertainty is perhaps the most important negative aspect of what many have considered to be the central feature of human life and action distinguished from lower forms of living systems' (Parsons 1980: 145).

Uncertainty and unpredictability are hereafter on the one hand, a specific human affair, on the other hand, they point to a fundamentally negative aspect of human life. Because of the uncertainty associated with not knowing the consequences of one's own actions creates threats, sets limits and restricts the controllability of the world. For Parsons uncertainty is therefore an anthropologically deep-seated negative experience, and similar evaluations are also found at authors such as Durkheim and Merton, which ultimately equate uncertainty with destructuring and anomie (see WohlrabSahr 1993: 17f.).

As long as insecurity and uncertainty prevent people at the complete mastery of the inner and outer nature, they are for Parsons a nuisance that must be removed and can be eliminated insofar as the capacity to deal with uncertainty increases systematically in the course of evolution. Although the man may have been overwhelmed with uncertainties at the beginning of the evolution, in time he learns to be aware of them and to successfully deal with them. Or in Parsons' own words:

'(...) in the process by which human individuals have become increasingly self-conscious and increasingly concerned to apply consciously formulated knowledge, the capacity to cope with uncertain contingencies very substantially increased' (Parsons 1980: 148). 
This is precisely the crucial second part of the standard position of the modernity - as long as the cognitive capacities grow together with the evolutionary progress in dealing with uncertainty and the predictability of the world continues to increase due to the progress of science, there is an inexorable decline of uncertainty - following the motto: provided time and money, everything can be made safe and secure.

It can be doubted that Parsons would have maintained this belief even after the experience of Harrisburg, Chernobyl, 9.11 or Fukushima. An opposite argument is formulated by Felix von Cube, with his thesis that people are always looking for active uncertainties in order to gain security. Since 'the turn of uncertainty into security is rewarded with passion' (Cube 1990: 11), uncertainty is not only a must, but also a positive element of evolutionary progress. Von Cube found only partial approval of this thesis in the scientific debates. But there are economists holding similar positive positions, although with very different theoretical justifications, such as the American uncertainty theorist Ronald Heiner $(1983,1985)$. Starting from the thesis that 'uncertainty generates flexibility' (Heiner 1985: 364) he describes uncertainty as a possibility forcing moment, without which neither innovation, nor social development would be possible. For Heiner a society can only remain viable, if it retains a certain 'level of uncertainty' (see Heiner 1983: 380). Similar estimates can be found at Aaron Wildavsky (1989: 48ff.) or at insurance companies like the Munic Re, which defended the thesis a quarter of a century ago:

'Uncertainty is next to existential diversity an important structural factor of social development. A general warranty against permanent security means stagnation, inaction, numbness.' (Bavarian Reinsurance 1987: 7).

Despite this, all parties (including Parsons) agree that the evolutionary progress leads to more security. However, this development is interpreted differently. Unlike Parsons, Heiner is not concerned with the abolition of uncertainty, but with the conscious cultivation and maintaining of adequate levels of uncertainty. A contrary assessment provides von Cube. He assumes 
that the transformation of uncertainty into certainty leads to the institutionalization of the growing safety level. But exactly this development, according to his thesis, sets the opposite free. Because growing security successes allow the assumption of new, previously unknown risks, which are bigger overall - a result which, given the major disasters in the 20th Century, is shared by very different authors.

The argumentations of Parsons, Heiner and von Cube, which are tangent is various points illustrate both the band width and the most important variants of today's debate about the social value of uncertainty and insecurity. In empirical terms, the perspective of Talcott Parsons still dominates. His perception of insecurity runs beyond its defence and repression also having a high degree of safety orientation. 'Uncertainties' appear at Parsons as an unavoidable nuisance that can only be overcome by the fact that they are made disappear as possible, so uncertainty is turned into security, ambiguity into clarity, and chaos into planning. As Helmut Wiesenthal has shown in his discussion of the figure of the "homo economicus', this look is in the social sciences similarly deeply rooted as in the usual common-sense ideologies. Ultimately, both here and there:

'(...) a pathology of uncertainty is suggested. Doers, actions and situations appear deficient to the extent they are affected by uncertainty.' (Wiesenthal 1990: 47).

Conversely, intentionality and situation control apply as a proof of a nondeficient action, which knows what it wants and aims to enlarge the space of controllable and to increase the social security level.

Even if the assertion of gradually declining levels of insecurity is still widespread - it has lost its meaning, facing spectacular engineering disasters and new political and social uncertainties. While losing its importance, one can also observe that it has never been undisputed. Thus, it has been assumed for a long time in the social policy debate that:

'(...) uncertainty... (is) the characteristic experience of human existence in the 20th century' (Möller 1960: 25). 
Anyone who accepts this can no longer comprehend uncertainty as an ultimately negative topic. Instead, it is an issue gaining relevance and imposing new theory perspectives in the framework of 'modern modernity'. In this sense, Helmut Wiesenthal calls for a reversal of the regulatory look à la Parsons. The base and reference point of sociological reconstructions should not be the individual striving for safer control of nature; instead of security rather 'genuine uncertainty as the raison d'être of actors and unsafe action contexts as products of the uncertainty deliberate action' (Wiesenthal 1990: 48) should be perceived - a change of perspective, which ultimately turn the view of the complexity towards the contingency of the social.

The fact that the forming of theory should be based rather on uncertainty than on allegedly growing certainties seems worth considering, not only given the empirically observable 'uncertainties burglaries'. In a systematic way also the 'undeterministic structure of events' (Bonatti 1984: 111ff.) agrees with this, as it is increasingly asserted in the science and probability theory discussions. However, this commitment is not a resounding vote of confidence to the uncertainty. Quite apart from those who hold to the traditional shear awareness optics, the turn to uncertainty is underlined completely differently, namely as an opportunity and threat alike. Or formulated by the example of Heiner and von Cube: for some (in this case Heiner) the commitment to the uncertainty is desired and positive; it points to the new flexibilities, greater contingency and more design options. For others however (in this case von Cube), it is enforced and negative; it points to new threats that can hardly be overcome, but pose the threat of self-destruction.

Parsons, von Cube and Heiner have not carried out any risk research in the strict sense, but developed different perspectives based on the assessment of (un-)certainty. The alternatives observed in their case can be identified in the development of risk research itself. As the relevant representations of the risk research development show, at least ${ }^{6}$ three perspectives can be differentiated: it began with the 'risk assessment' of the

\footnotetext{
6 See Banse (1996), Bernstein (1997), Metzner (2002), Renn et al. (2007).
} 
first generation, which prevailed between 1950 and 1975. This highly scientific and technical oriented perspective operated with the idea of scientifically 'objective' risks which are clearly identified and evaluated by experts in the context of probabilistic approaches (e.g. Rowe 1993). However, this perspective that is highly compatible with the 'standard position' encountered two problems over the time: Firstly, the relevant models proved incomplete and only partially verifiable, particularly for complex applications such as nuclear power plants (see Häfele 1974). On the other hand, just during the political debates about nuclear technology it turned out that the laity differently assessed the 'objective' risks identified by the experts and considered smoking, for example, harmless as compared to nuclear technology.

This observation led to the recovery of the psychological risk research that deals with the 'subjective' perception of risk and which was the centre of attention between 1970 and 1990.7 Relevant researches have questioned in some way the universal validity claim of the technical concept of risk. But it became clear that there is no such risk. Moreover, risks in everyday life are experienced as part of challenge and opportunity, but at least as often as threat and danger. That's why the popular distinction between 'risk-taking' and 'risk-averse' people is also of limited value. To clarify the conditions under which people assume or reject uncertainty is far more important. According to the findings of psychological research, this depends primarily on three conditions: For one, the people are more willing to take risks, the more the uncertainty in question is classified as 'old' and thus as known, familiar and potentially controllable. Conversely, uncertainties are rejected if they are 'new', unknown, unfamiliar and therefore appear exactly as potentially unmanageable. The second dimension refers to the type of risk exposure, and ultimately to the definition of risk and danger. People perceive an uncertainty/insecurity as a challenge especially when they expose themselves to it, like driving a car, smoking, or in recreational sports,

\footnotetext{
7 For comprehensive presentation of these approaches see most recently Wiedemann and Mertens (2005) and Renn et al. (2007: 77ff.).
} 
due to their own decision and thus they experience it as a manageable risk and opportunity. The situation is different when the questioned uncertainty comes from outside, is not assumed voluntarily and is thus seen as an uncontrollable threat. Finally, as a third dimension the perception of potential damage must be noted: if the potential damage, as in the case of a volcanic eruption or a meltdown, is considered 'extraordinary', 'fatal' and 'sudden', then one would not want to expose himself to this danger in any way. If, however, the potential damage is perceived as 'normal', not 'deadly' and 'chronic', the willingness to engage in uncertainties such as risk sports or smoking increases.

Contrary to initial assumptions of risk research, this behaviour is not irrational at all. The laymen could mistake their evaluations. But if they are particularly risk averse, when the questioned uncertainties are imposed on them, appear as unknown or uncontrollable, and are connected to a potential of catastrophic loss, then this is a perfectly rational adjustment in the sense of 'bounded rationality' (March and Simon 1958: 137ff), or the 'social rationality' of Perrow (1987 [1984]: 368ff.). Although it does not necessarily correspond to the 'absolute rationality' of experts (see Bonß 1995: 294ff.), therefore it cannot simply be brushed aside because the certainty of experts is usually incomplete as well. It is this insight that is the basis for the 'risk assessment' of the third generation, as it has become more and more important in the German discussion since the mid-80s. In this view, risks and their management appear more as social construction and communication problem ${ }^{8}$. Even the insurance industry, which otherwise mainly works with probabilistic models, now claims: 'Risk is a construct' (Bayerische Rück 1993), and since it can be built in different ways, it must be communicated through the different perceptions - true to the motto: 'How safe is safe enough' (Starr 1969: 1233), and what kind of safety do we actually strive for?

\footnotetext{
${ }^{8}$ Among the various types of risk communication research see Kruger and Russ-Mohl (1991), Bavarian Reinsurance (1993), Morgan et al. (2002), Renn et al. (2007: 111ff.), as well as Lundgren and McMakin (2008)
} 
Compared to English-speaking regions, where in the meanwhile numerous 'risk manuals' and 'Handbooks of Risk Communication' have appeared (Lundgren and McMakin 2008), the European and especially the German-speaking risk communication research is underdeveloped, and yet also consists of a rather diffuse variety of approaches. There are attempts to operate risk assessment more historically than the technical genesis research (see Dierkes 1987). In addition, there are different approaches to distinguish 'risk types', each requiring different reactions and forms of communication (see WBGU 1998: 58ff), and finally there are attempts to define and characterize in more detail the various forms of risk communication. Starting from the definition of various functions of risk communication, for example the race between the forms of communication, documentation, information, dialogue and participation (Renn et al. 2007: 113f.), which do not only refer to different degrees of decreased experts centeredness, but also to a growing pluralisation of risk and safety structures, which may not be longer pitted against each other, but are to be brought into an open communication process.

\section{Dialectics of (un-)certainty. Or: Plea for a new risk culture}

Almost 25 years ago, Aaron Wildavsky initiated a symposium on 'Risk, Safety and Capitalism' (Wildavsky et al. 1989). The occasion for this symposium was a dispute over the question of what risks must be assumed by modern societies and which not. Wildavsky's opponents represented in this context an absolute-safety-oriented position; given the experience of Harrisburg and Chernobyl risks were only acceptable, if they had been previously fully validated and transformed into safety. Wildavsky countered that, with such an attitude, absolutely no innovation would be possible. Although he was not referring to the Knightian distinction between 'risk' and 'uncertainty'. But with Knight one could formulate Wildavsky's position also that innovations are ultimately possible only if we assume not only fully verifiable and therefore ultimately safe 'risks', but also 
'uncertainties', which ultimately can be managed through the 'abbreviation rules'.

The fact that Wildavsky did not use the Knightian distinction, but rather unceremoniously called for an unbridled risk culture capitalism appears analytically shortening and, given the current financial crisis in empirical terms, hardly convincing. Nevertheless, his basic argument was evident, because the discovery of something new is not possible if based on complete safety and controllability. Who wants to find new facts must ultimately be involved with insecurities of the type 'uncertainties'. Many researchers, explorers and entrepreneurs have done exactly the same, both with successful and with some precarious consequences. Marie Curie, for example, experimented with radon without major safety precautions, and her death caused by anaemia is likely to be attributed to her long-term handling of radioactive elements. The same applies to Otto Hahn and Lise Meitner, who did not die as a result of their experiments; however, the German Museum of Munich did not expose their original worktable, as it was too contaminated by today's standards. While Curie, Hahn and Meitner could hardly work in accordance with current safety standards, they did not exactly know the dangers they were exposing themselves to. Nevertheless the reason why their behaviour did not generate any questions, is probably because they were successful; the adverse consequences, if they were known at all, seemed to be justified by the success. This pattern was certainly the more problematic the more clearly that the structural change of uncertainty came to light, as it is described in the definition of 'old' and 'new' risks.

The now highly differentiated definition of 'old' and 'new' risks goes back to Ulrich Beck and his analysis of the 'risk society'" (Beck 1986). There, Beck had suggested that the classic risk concepts and models of modernity, as represented by the bold engineer, the daring entrepreneur or the risk athletes, can hardly be applied to complex risk systems, such as nuclear power plants, genetic engineering test facilities or global equity markets. For complex systems and at the same time scientized risk, it must be operated rather with other uncertainty and loss expectations (see Beck 2007: 11ff.). It 
cannot be assumed that the uncertainties in question, as in the 'old' risks, are completely known, predictable and verifiable. Due to the complexity of the systems, there are rather problems of identification, causation and mitigation of uncertainties (see Brüggemeier 1991: 297ff.); they are often only partially known, and where they can also be checked in a limited manner, unexpected interactions, intervening variables and unintended side-effects cannot be excluded.

Figure 2: 'Old' Risks vs. 'New' Risks

\begin{tabular}{|c|c|}
\hline 'Old' risks & 'New' risks \\
\hline $\begin{array}{l}\text { Examples: } \\
\text { - the bold engineer } \\
\text { - daring business man } \\
\text { - risk sportsman }\end{array}$ & 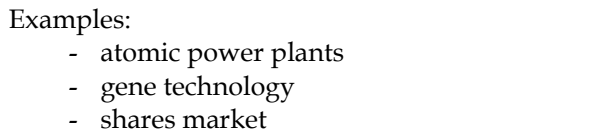 \\
\hline $\begin{array}{l}\text { Assumption of uncertainty: } \\
\text { - As a rule, risks are fully known. } \\
\text { - They can be calculated; unexpected } \\
\text { interactions and unwanted } \\
\text { consequences can be omitted. } \\
\text { - Risks can be checked completely. }\end{array}$ & $\begin{array}{l}\text { - } \quad \text { Risks are not entirely known. } \\
\text { - Unexpected interactions, intervening } \\
\text { variables and unintended consequences } \\
\text { cannot be excluded. } \\
\text { - Risks cannot be checked completely, but they } \\
\text { remain 'hypothetical'. }\end{array}$ \\
\hline $\begin{array}{l}\text { Damage expectancies: } \\
\text { - As a rule, potential damages are limited } \\
\text { and therefore they can be compensated } \\
\text { with money, }\end{array}$ & $\begin{array}{l}\text { - Since the boundaries expand in time, at social } \\
\text { and material level, potential damages cannot } \\
\text { be compensated with money. }\end{array}$ \\
\hline $\begin{array}{l}\text { Risk related discourses focus on: } \\
\text { - wins and losses }\end{array}$ & - losses and damages \\
\hline $\begin{array}{l}\text {-> 'Courage for risk' / willingness to carry a risk } \\
\text { for Safety certainty }\end{array}$ & $\begin{array}{l}\text {-> 'Fear for danger' / risk avoidance because of } \\
\text { Unsafety certainty. }\end{array}$ \\
\hline
\end{tabular}

Similar differences occur for the damage expectancies. While in the case of 'old' risks one can work with the assumption that the damages, even though they may be high in some cases, are limited and can be compensated, it is not the case for 'new' risks. Because in this case, potential damages are expanded in time, materially and socially. Radioactive clouds do not stop at national borders, the half-life of polluted substances can amount to 
thousands of years, and a genetic engineering accident or the introduction of organisms in areas where they have no natural enemies, may sustainably affect the livelihoods of entire regions. In all these cases, the damages due to the dissolution and the side effects can often hardly be specified and certainly cannot be compensated by money. Still there are certainly attempts to adhere to the principle of compensability - German nuclear power plants, for example, must be insured against the worst case scenario. But if one considers the level of services to be provided by the companies for financial security (DM 500 million or $€ 256$ million), it can ultimately only be spoken by a symbolic liability. ${ }^{9}$

Given the fundamental differences regarding uncertainty assumptions and damage expectations it is no wonder that the risk related discourses differ for 'old' and 'new' risks. With the old risks that are associated with positive role models such as the bold engineer or the successful entrepreneur, the slogan 'take risks' comes out in the relevant discourses usually comparatively good. Because this uncertainty is addressed on the basis of a fundamental security assurance - however that may be justified in detail. The situation is very different for the 'new' risks. If these are not actively received and perceived as temporally, materially and socially expanded, then safe uncertainty replaces safe certainty. As a result of this uncertainty, in turn, the 'courage to take risks' is almost inevitably replaced by a 'fear of danger', and this fear is not irrational at all; because of the specific nature of the 'new' risks rather, it can be highly rational.

Regardless of that, the analytical delineation of 'old' and 'new' risks is not enough. Even if it is accepted that there are two fundamentally different uncertainty types that cannot be measured by the same standards, there are still substantial differences, depending on whether the two types of risk are

\footnotetext{
9 This also applies to a more detailed consideration (see Grawe 2003, whose interpretation of the facts I do not necessarily share). Although the operators are beyond the 256 million with all their assets and there are additional commitments of the federal government in the amount of $€ 2.5$ million per claim. But the operators are organized as subsidiaries that are likely to go bankrupt in case of damage, and the commitment of the federal government only makes it clear that the coverage of actual GAU is much too low (whereby in serious cases, the damages are also unlikely to be actuarially manageable).
} 
approached from the perspective of security-oriented 'standard position' or from the perspective of uncertainty oriented 'alternative position'. From the perspective of the 'standard position', as advocated by Durkheim to Parsons, uncertainty is presented as a nuisance to be eliminated through continuous improvement in safety and security levels. Dealing with the 'old' risks is basically focused on certainty and goes beyond a 'control-oriented management of uncertainty' - along the lines: one can assume the questioned risks, because they can be calculated, checked completely and this way they can be transformed into long-term certainties.

When dealing with 'new' risks, the position is not so clear. Here two variants can be distinguished: on the one side are those who carry the promise of controllability to the new risks and act according to the motto: 'Provided time and money everything can be made safe and secure'. Hence the long time dominant position of a 'cumulative risk management' results, which can be characterized as follows: if it is possible to provide adequate capacity and to further refine the available risk models, this will succeed in the long term, to make the 'new' risks as manageable as the old. However, the advocates of this position are now no longer in the majority. Rather, a second parallel position occurs running beyond a 'risk denial'. Prototypical for this position were the opposers of Aaron Wildavsky at the conference of 1989. The fact that this (like many other risk critics) ultimately argued from the perspective of the conventional position is often overlooked. But they also understood uncertainty as a nuisance that had to be eliminated and that is why they had an extremely high safety orientation. The 'risk denial' results in this case more of the disappointment that the risk research has not redeemed their original promises. Because if enough certainty cannot be guaranteed and if residual uncertainties remain, then one can refuse to take new risks. ${ }^{10}$

\footnotetext{
10 The fact that in front of the background of the standard position it can be switched between 'cumulative risk handling' and 'refusal to take the risk', depending on the situation is presently shown by the behavior of CSU in case of gene-technologically modified plants (see Spiegel-Online v. 24.4.2009, http://www.spiegel.de/politik/deutschland/0,1518,620665,00. html).
} 
The handling of uncertainty from the perspective of the alternative positions looks different. As long as uncertainty does not appear as annoyance but as productivity resource, the classic order and certainty orientation is not dominant, but an orientation towards uncertainty, that could be described in various manners. The switch is already shown during the handling of 'old risks'. Old risks are debated less with regard to their domination and elimination, but the emphasis is on the perspective of an innovation-oriented behaviour, which, based on manageable risk, focuses on an experimental discovery. This does not mean that safety measures play no role. But certainty and innovation are seen in a tensioned relation and the production of certainty is not defined solely through measurability and probability, but also by a problem of experience and intuition.

Figure 3: Handling 'old' and 'new' risks

\begin{tabular}{|c|c|c|}
\hline & ‘Old' risks & 'New' risks \\
\hline $\begin{array}{l}\text { From the perspective of the } \\
\text { conventional standard } \\
\text { position } \\
\text { (Uncertainty as annoyance } \\
\text { to be removed; certainty } \\
\text { orientation dominant) }\end{array}$ & $\begin{array}{l}\text { 'Control oriented handling of } \\
\text { uncertainty': } \\
\text { One takes risks because one can } \\
\text { calculate, completely check and } \\
\text { control them }\end{array}$ & $\begin{array}{l}\text { a) 'Cumulative risk handling': } \\
\text { New risks shall become } \\
\text { controllable through the } \\
\text { permanent research } \\
\text { b) 'Risk refusal': } \\
\text { Justification: One can rely } \\
\text { only on controllable risks }\end{array}$ \\
\hline $\begin{array}{c}\text { From the perspective of } \\
\text { the alternative } \\
\text { position } \\
\text { (Uncertainty as } \\
\text { productivity resource; } \\
\text { uncertainty orientation } \\
\text { dominating) }\end{array}$ & $\begin{array}{l}\text { 'Innovation oriented handling of } \\
\text { uncertainty': } \\
\text { One takes foreseeable risks in } \\
\text { order to discover something new }\end{array}$ & $\begin{array}{l}\text { A 'new culture of the uncertainty' } \\
\text { with 'risk responsible actors', who } \\
\text { can make the difference between } \\
\text { 'risk types', create 'situative } \\
\text { certainty' in time and who build } \\
\text { not only on control, but also on } \\
\text { trust }\end{array}$ \\
\hline
\end{tabular}

The difference regarding the access is more emphasized in case of new risks. Because, in this case, the alternative is not 'complete risk elimination' or 'risk denial'. Instead, it comes to something like a 'third way', namely a 'new culture of uncertainty' beyond the alternative of 'risk elimination' and 'risk denial'. The starting point of this path is a basic commitment to uncertainty as a basis and reference point of human life, while rejecting the 
idea of the possibility of complete certainty. As Zygmunt Bauman mentions in his works about the 'Modernity and Ambivalence' (Bauman 1992), such a cancellation is indeed difficult because the modern was oriented from the beginning to the idea of clear order and to the eradication of any ambiguities. However, Bauman says - and he meets with Bruno Latour (1995) as well as with the theory of 'reflexive modernization' (Beck 1993, Beck, Bonß and Lau 2001) - that the obsession with order and clarity can be preserved only at the price of deadly exclusion and, with modernization of modernity, this leads to more problems and perplexities. Or the example: the more the clarity and measurability-based risk and safety research progresses, the more obvious is that they cannot or only at the price of precarious side effects reach their goal.

It follows not a rejection of the research oriented to eliminate uncertainty and measurability. But the least one must not be the only reference point. Rather, an uncertainty-oriented pluralism of both the risk discourses and the risk research is desired, in the course of which a specific type of actor could appear, namely as the 'risk-aware' as 'risk-responsible' actor. Such actors, independently whether at expert or Laymen level are characterized by the fact that they can make the difference between various 'risk types' and during the handling of uncertainty they county not only on control and measurability, but also on trust, experience and intuition. Against this background, they do not understand security as an order problem, rather than a risk or, more precisely, as an 'uncertainty' question. And this question never can be answered definitively, but only time and depending on the situation. These situational solutions are at the end of professionally and equally democratic values and communication process that is not based on uncertain certainties but on certain uncertainties. Whether and how such communication processes can be organized is an open question. But it is essential to strive for it, if the 'value idea' certainty is to be developed successfully in the future. 


\section{References:}

Banse, Gerhard. 1996. "Herkunft Und Anspruch Der Risikoforschung." In Risikoforschung Zwischen Disziplinaritat Und Interdisziplinaritat: Von Der Illusion Der Sicherheit Zum Umgang Mit Der Unsicherheit, edited by Gerhard Banse, 15-72. Berlin: Sigma.

Bauman, Zygmunt. 1992. Moderne und Ambivalenz: das Ende der Eindeutigkeit. Hamburg: Junius.

Bayerische Rückversicherung, ed. 1987. Gesellschaft Und Unsicherheit. Karlsruhe: Verlag Versicherungswirtschaft.

Bayerische Rückversicherung Aktiengesellschaft, ed. 1993. Risiko Ist Ein Konstrukt: Wahrnehmungen Zur Risikowahrnehmung. München: Knesebeck.

Bechmann, Gotthard. 1993. "Risiko als Schlüsselkategorie der Gesellschaftstheorie." In Risiko und Gesellschaft: Grundlagen und Ergebnisse interdisziplinärer Risikoforschung, edited by Gotthard Bechmann, 237-275. Opladen: Westdeutscher Verlag.

Beck, Ulrich. 2007. Weltrisikogesellschaft. Auf der Suche nach der verlorenen Sicherheit. Frankfurt am Main: Suhrkamp.

Beck, Ulrich. 1993. Die Erfindung Des Politischen: Zu Einer Theorie Reflexiver Modernisierung. Frankfurt am Main: Suhrkamp.

Beck, Ulrich. 1986. Risikogesellschaft: Auf Dem Weg in Eine Andere Moderne. Frankfurt am Main: Suhrkamp.

Becker, Ulrike, Wolfgang Bonß, and Christoph Lau. 2001. "Theorie Reflexiver Modernisierung - Fragestellungen, Hypothesen, Forschungsprogramme." In Die Modernisierung Der Moderne, edited by Ulrike Beck and Wolfgang Bonß. Frankfurt am Main: Suhrkamp: Suhrkamp.

Bernstein, Peter L. 1997. Wider die Götter: die Geschichte der modernen Risikogesellschaft. München: Gerling Akademie Verlag.

Bonß, Wolfgang. 1995. Vom Risiko. Unsicherheit und Ungewißheit in der Moderne. Hamburg: Hamburger Edition.

Bonß, Wolfgang. 1982. Die Einübung des Tatsachenblicks. Zur Struktur und Veränderung empirischer Sozialforschung. Frankfurt am Main: Suhrkamp.

Bonß, Wolfgang, Felicitas Eßer, Joachim Hohl, Helga Pelizäus-Hoffmeister and Jens Zinn. 2004. "Biographische Sicherheit". In Entgrenzung und Entscheidung: Was ist neu an der Theorie reflexiver Modernisierung, edited by Ulrich Beck and Christoph Lau, 211-233. Frankfurt: Suhrkamp.

Brockhaus. 2002. Der Brockhaus in Text und Bild. Edition 2002 (Electronic 
version). Mannheim: Bibliographischer Verlag.

Brüggemeier, Gert. 1991. “Jenseits des Verursacherprinzips? Zur Diskussion um den Kausalitätsnachweis im Umwelthaftungsrecht". Kritische Vierteljahresschrift für Gesetzgebung und Rechtswissenschaft 74 (3-4): 297 $-310$.

Cube, Felix v. 1990. Gefährliche Sicherheit. Die Verhaltensbiologie des Risikos. München: Piper.

Desrosières, Alain. 2005. Die Politik der großen Zahlen. Eine Geschichte der statistischen Denkweise. Berlin, Heidelberg, New York: Springer.

Dieckmann, Andreas. 2009. Spieltheorie. Einführung, Beispiele, Experimetne. Reinbek: Rowohlt.

Dierkes, Meinolf. 1987. “Technikgenese als Gegenstand sozialwissenschaftlicher Forschung. Erste Überlegungen". In Verbund sozialwissenschaftlicher Technikforschung. Mitteilungen 1: 154-170

Douglas, Mary. 1963. The Lele of Kasai. London: Oxford-University Press.

Douglas, Mary and Aaron Wildavsky. 1982. Risk and Culture: An Essay on the Selection of Technical and Environmental Dangers. Berkeley: University of California Press.

Gehlen, Arnold. 1957. Die Seele im technischen Zeitalter: Sozialpsychologische Probleme in der industriellen Gesellschaft. Hamburg: Rowohlt.

Gehlen, Arnold. 1940. Der Mensch. Seine Natur und seine Stellung in der Welt. Berlin: Junker und Dünnhaupt.

Gigerenzer, Gerd. 2007. Bauchentscheidungen: Die Intelligenz des Unbewussten und die Macht der Intuition. München: Goldmann.

Grawe, Joachim. 2003. "Sind die deutschen Kernkraftwerke ausreichend versichert?". http:/ / www.energie-fakten.de/.

Hacking, Ian. 1975. The Emergence of Probability. A Philosophical Study of Early Ideas about Probability, Induction and Statistical Inference. Cambridge, London, New York, Melbourne: Cambridge University Press.

Heiner, Ronald A. 1983. "The Origin of Predictable Behaviour." American Economic Reveiw 73 (4): 560-595.

Heiner, Ronald A. 1985. "Origin of Predictable Behaviour: Further Modelling and Applications." The American Economic Review 75 (2): 391-396.

KarstadtQuelle Versicherungen. 2008. “Eigenverantwortung 2008 - Der UnMut Zur Vorsorge." http://www.eigenverantwortung.de/.

Kaufmann, Franz-Xaver. 2003. "Sicherheit: Das Leitbild beherrschbarer Komplexität". In Wohlfgahjrtsstaatliche Grundbegriffe. Historisch eund aktuelle Diskurse, edited by Stephan Lessenich, 73-104. Frankfurt am Main: Campus. 
Kaufmann, Franz-Xaver. 1973. Sicherheit als soziologisches und sozialpolitisches Problem. Untersuchung zu einer Wertidee hochdifferenzierter Gesellschaften. Stuttgart: Enke.

Knight, Frank Hyneman. 1965 [1921]. Risk, Uncertainty and Profit. Chicago: University of Chicago Press.

Krüger, Jens and Stephan Ruß-Mohl, eds. 1991. Risikokommunikation. Technikakzeptanz, Medien und Kommunikationsrisiken. Berlin: Edition Sigma.

Kunz, Volker. 2004. Rational Choice. Frankfurt: Campus.

Latour, Bruno. 1995. Wir sind nie modern gewesen. Versuch einer symmetrischen Anthropologie. Berlin: Akademie Verlag.

Lundgren, Regina and Andrea McMakin. 2008. Risk Communication. A Handbook for Communicating Environmental, Safety, and Health Risks. Chichester, Oxford: Wiley-InterScience.

March, James G. and Herbert A. Simon. 1958. Organisations. New York: John Wiley and Sons.

Metzner, Andreas. 2002. Die Tücken der Objekte. Über die Risiken der Gesellschaft und ihre Wirklichkeit. Frankfurt am Main: Campus.

Morgan, M. Granger, Baruch Fischhoff, Ann Bostrom, Cynthia J. Atman. 2002. Risk Communication. A mental models approach. New York: Cambridge University Press.

Parsons, Talcott. 1980. "Health, uncertainty and the action structure". In Uncertainty. Behavioural and Social Dimensions, edited by Seymour Fiddle, 145-163. New York: Praeger.

Perrow, Charles. 1987 [1984]. Normale Katastrophen. Die unvermeidbaren Risiken der Großtechnik. Frankfurt am Main: Campus.

Porter, Theodore M. 1986. The Rise of Statistical Thinking 1820-1900. Princeton: Princeton University Press.

Reichenbach, Hans. 1935. Wahrscheinlichkeitslehre. Eine Untersuchung über die logischen und mathematischen Grundlagen der Wahrscheinlichkeitsrechnung. Leiden: Sijthoff.

Renn, Ortwin, Pia-Johanna Schweizer, Marion Dreyer, and Andreas Klinke. 2007. Risiko: Über den gesellschaftlichen Umgang mit Unsicherheit. München: Oekom.

Rowe, William D. 1993. "Ansätze und Methoden der Risikoforschung". In Riskante Technologien: Reflexion und Regulation, edited by Wolfgang Krohn and Georg Krücken, 45-78. Frankfurt am Main: Suhrkamp. Sofsky, Wolfgang. 2005. Das Prinzip Sicherheit. Frankfurt am Main: Fischer.

Starr, Chauncey. 1969. "Social Benefit Versus Technological Risk." Science 165 (3899): 1232-1238. (German translation 1993. In: Risiko und 
Gesellschaft, edited by Gotthard Bechmann, 3 -25. Westdeutscher Verlag: Opladen).

Traufetter, Gerald. 2009. Intuition: Die Weisheit der Gefühle. Reinbek: Rowohlt. Wartofsky, Marx W. 1986. "Risk, Relativism and Rationality". In Risk Evaluation and Management, edited by Vincent T. Covello, Joshua Menkes and Jeryl Mumpower, 131-154. New York, London: Plenum Press.

Weber, Max. 1919. "Vom Inneren Beruf Zur Wissenschaft." In Max WeberSoziologie, Weltgeschichtliche Analysen, Politik, edited by Johannes Winckelmann, 311-340. Stuttgart 1968: Kröner.

Weber, Max. 1980 [1922]. Wirtschaft und Gesellschaft: Grundriß der verstehenden Soziologie. Tübingen: Mohr.

Wiedemann, Peter M. and Johannes Mertens. 2005. "Sozialpsychologische Risikoforschung." Technikfolgenabschätzung -Theorie und Praxis 14 (3): 38-45.

Wiesenthal, Helmut. 1990. Unsicherheit und Multiple-Self-Identität: Eine Spekulation über die Voraussetzungenn strategischen Handelns. Köln: MPIFG Discussion Paper.

Wiesenthal, Helmut. 1987. "Rational Choice - Ein Überblick Über Grundlinien, Theoriefelder Und Neuere Themenakquisition Eines Sozialwissenschaftlichen Paradigmas." Zeitschrift Für Soziologie 16 (6): 434-449.

Wildavsky, Aaron, et al. 1989. Symposium: "Risk, Safety and Capitalism". Society 27(1). Special issue.

Wohlrab-Sahr, Monika. 1993. Biographische Unsicherheit. Formen weiblicher Identität in der "reflexiven Moderne": Das Beispiel der Zeitarbeiterinnen. Opladen: Leske and Budrich. 